\title{
Staff Absenteeism in Public Health Facilities of Uganda: A Study in Bushenyi District on Contributing Factors
}

\author{
Nancy Nyasuguta Nyamweya ${ }^{1,2 *}$, Peter Yekka ${ }^{1,3}$, Ronny Drasi Mubutu3, \\ Keneth Iceland Kasozi ${ }^{4}$, Jane Muhindo ${ }^{{ }^{*}}$
}

${ }^{1}$ Department of Public Health, School of Health Sciences, Nursing and Midwifery, Mountains of the Moon University, Fort Portal, Uganda

${ }^{2}$ Kyeizooba Health Center III, Kyeizooba Sub-county-Igara East Constituency, Bushenyi District Local Government, Bushenyi, Uganda

${ }^{3}$ Department of Public Health, School of Allied Health and Medicine, Kampala International University Western Campus, Bushenyi, Uganda

${ }^{4}$ Department of Physiology, Faculty of Biomedical Sciences, Kampala International University Western Campus,

Bushenyi, Uganda

Email: *nanond7@gmail.com and muhindojane@gmail.com

How to cite this paper: Nyamweya, N.N., Yekka, P., Mubutu, R.D., Kasozi, K.I. and Muhindo, J. (2017) Staff Absenteeism in Public Health Facilities of Uganda: A Study in Bushenyi District on Contributing Factors. Open Journal of Nursing, 7, 1115-1130. https://doi.org/10.4236/ojn.2017.710081

Received: June 11, 2017

Accepted: October 14, 2017

Published: October 17, 2017

Copyright ( $) 2017$ by authors and Scientific Research Publishing Inc. This work is licensed under the Creative Commons Attribution International License (CC BY 4.0).

http://creativecommons.org/licenses/by/4.0/ (c) $\underset{\mathrm{EY}}{\text { (i) Open Access }}$

\begin{abstract}
Background: Staff absenteeism is a global challenge in health care service delivery that has not spared any country. Aim: This was to assess the factors contributing to staff absenteeism in public health facilities in Bushenyi District of Uganda. Method: This was a cross sectional study conducted for a period of 3 months in which data were collected using a questionnaire and interviews. Results: Majority of participants were females (66.4\%) which 50\% in the age of 31 - 45 years. The study showed that residing outside the health facility (42.1\%) i.e. walking distances over $10 \mathrm{~km}$ to get to work was a challenge. Family conflicts, overstay in one workstation without rotations to other major health facilities and drug abuse as well as inadequate supervision were major contributing factors to absenteeism $(\mathrm{P}<0.05)$. This is complicated by increased administrative duties coupled with poor enumeration and motivation in the health facilities visited. However over $50 \%$ of the participants reported never to have left their work stations without permission, thus showing that the challenges faced in a majority of health centers in rural communities warrant national support through improved motivation of staff working in the challenging communities. Conclusion: Staff absenteeism in rural communities is a major challenge that needs a multi-sectorial approach for its effective management, thus showing a need to revise policy in the health sector.
\end{abstract}




\section{Keywords}

Staff absenteeism in Uganda, Uganda Health Care, Nurses in Africa

\section{Introduction}

Absenteeism is a global challenge in health care service delivery that has not spared any country [1]. Locally, absenteeism is understood as being completely out of work station or arriving at the work station later than scheduled or leaving the work station early than scheduled without any permission from the prevailing authority [2]. Absenteeism also implies absences that are avoidable, habitual and unscheduled, thus a source of irritation to employers, co-workers and community served [3]. Such absence is not only disruptive to proper work schedules, efficiency, output, and costly to organizations and the economy as a whole, but also increases complications, disability and death from otherwise manageable conditions [4]. In Uganda, Absenteeism is the single largest waste factor in the public health sector in the country [5]. The poor attitude of health workers to clients affects utilization of services. Leadership and management of human resources are also weak at all levels [3]. Overall absenteeism at the health centers in Uganda has been recognized as a major threat to the national healthcare system, just like in any other developing country with a low staff to patient ratio [6].

Staff absenteeism in Bushenyi District is alarming, and yet factors affecting absenteeism are not fully understood and documented to guide managers for appropriate action. According to [7], health worker's absenteeism in Bushenyi District stands at $47.9 \%$ thus affecting all the health facilities in the district. In Bushenyi district, health workers are committed to disciplinary committee for absenteeism [8] with many cases remaining unreported and documented. Although the culprits have appeared before disciplinary committees, staff absenteeism has continued in the district [3]. It also results into work overload, fatigue and low morale among the few staff in station which in turn reduces effectiveness in quality of service delivery [6]. Quality health care service delivery needs highly motivated and available staff in work stations [9], and this continues to be elusive in Bushenyi district due to this continued menace [8]. Therefore the findings of this study are beneficial to the Ministry of Health $(\mathrm{MOH})$ generally and the management of the decentralized health centers to appreciate and address the causes of health workers' absenteeism at work. It may also help improve health service delivery and subsequent improvement in peoples' healthcare and standards of living in Bushenyi district.

\section{Methodology}

\subsection{Study Design}

This was a descriptive cross-sectional survey design because it best provides the 
necessary information across a big population on the prevailing situation at the time. Quantitative and qualitative approaches used helped in describing the statistical relations and informed opinions of the respondents on the variables respectively. Important study variables included: population demographics, personal and hospital factors responsible for the propagation of absenteeism in the health centers.

\subsection{Study Area}

The study was carried out in Bushenyi district, targeting all the 24 public health facilities. The facilities included one health center IV, eight health center III's and fifteen health center II's. Bushenyi district is in the western Uganda region in Ankole sub region. It covers a total area of $942.3 \mathrm{sq} \mathrm{km}$ with a population of 235,621 according to 2014 population census. Kampala, the national capital and largest city in the country lies approximately $323 \mathrm{~km}(201 \mathrm{mi})$, by road to the east of Bushenyi. The coordinates of the town are $0^{\circ} 32^{\prime} 30.0^{\prime \prime S} 30^{\circ} 11^{\prime} 16.0^{\prime \prime} \mathrm{E}$ (Latitude: -0.541667 ; Longitude: 30.187778 ). The district is bordered by: Rubirizi district to the northwest, Buhweju district to the northeast, Sheema district to the east, Mitooma district to the south and Rukungiri district to the west.

\subsection{Study Population}

The study population was the health workers in Bushenyi district. The minimum qualification of the population was at least ordinary level certificate of Uganda or its equivalent. Their common language is Runyankole-Rukiga and majority of them are Christians with some Muslims. Agriculture forms the backbone of the economy of the people in this area and it is practiced on the subsistence level, though there are some crops which are grown for commercial purposes, some of the crops grown include: Coffee, Bananas, Beans, Maize and Groundnuts. Livestock is kept in many areas of the district including cattle, goats, sheep and poultry. People in Bushenyi district like parting, drinking among other social life they enjoy.

\subsection{Target Respondents}

The target population was the health workers in public health facilities in $\mathrm{Bu}$ shenyi district. These included: Doctors, Clinicians, Nurses, Midwives, Nursing Assistants, Porters, Records Assistants, Dental Health Officers, Security Guards, Laboratory Technicians and Assistants plus Health Assistants who in total were 235.

\subsection{Sample Size Determination}

This was done by using a sample size determination table by Morgan [10]. The minimum sample size was 152 . The Confidence Level $=95 \%$, and Margin of Error $=5 \%$. Therefore to cater for the non-respondents the researcher increased the sample size by calculation using margin error. i.e. $5 / 100 \times 152=7.6$ which 
was 8 respondents. So the researcher used a sample size of 160 respondents.

\subsection{Sampling Procedures}

The facilities and health workers were put in clusters according to level and cadres respectively, and then selected by simple random sampling technique to participate in the study while the managers were purposively selected from the fifteen health facilities which were included in the study. Since there was one health Centre IV, it was automatically included in the study. While health Centre III's and health Centre II's, they were sampled using a simple random sampling. The health workers were proportionally sampled in their different cadres then in getting specific respondents for the study, simple random sampling technique was used.

\subsection{Selection of Respondents}

\subsubsection{Inclusion Criteria}

The study involved all health workers in public health facilities in Bushenyi district of both sexes and of sound mind. It involved those who were on duty during the research and who consented to participate in the study. It also included the staffs that had finished a period of 12 months and above without any disruption in that particular facility.

\subsubsection{Exclusion Criteria}

The study excluded staff members who were on any kind of leave, those who did not consent, those who had not finished a period of at least 12 months in that particular health facility and those who were practicing from that facility but were not employed by Bushenyi local government.

\subsection{Methods of Data Collection}

The questionnaire had variables on age, marital status, education level, work experience, distance from the hospital, accommodation, supervisor ship, family challenges, history of individual absenteeism and work motivation as well as workplace administration. Self-administered questionnaires were issued to the health workers and collected after filling in. Self-administered questionnaires were used because the health workers were literate and committed to fill in the questionnaires at their convenience to minimize interference with their daily activities. The interview guide was also used as guide to the managers of the public health facilities to validate the reports that had been made.

\subsection{Data Management, Presentation and Analysis}

Data collection sheets were checked for completeness and accuracy. The responses in the questionnaire were coded, entered into MS Excel version 2013 and exported into SPSS Version 20 for analysis. Chi-square tests were conducted and significance was taken when $P<0.05$. 


\section{Results}

\subsection{Social Demographic Characteristics Affecting Health Staff Absenteeism}

Majority of the participants were between 31 - 45 yrs and of these $37.5 \%$ were females, $77 \%$ of the participants were married and females were the majority (52\%). Furthermore, $97.4 \%$ had acquired tertiary education of which $64.5 \%$ were female. $42.8 \%$ of the participants had spent 2 - 5 years in service and of these $28.3 \%$ are females. $42.1 \%$ resided away from the health facility and majority $28.3 \%$ were females. Of those who resided away $44.45 \%$ reside $>15 \mathrm{~km}$ from health facility and majority were females. Further analysis of the study socio-demographic variables with sex showed no significant differences $(P>0.05)$ in this particular study is as shown in Table 1 and Figure 1.

\subsection{Personal Factors Contributing to Staff Absenteeism.}

The study showed that family conflict (53.9\%), overstay in one workstation without rotation $(46.4 \%)$ and drug substance abuse $(27.2 \%)$ as significant $(\mathrm{P}<$ $0.05)$ personal factors in health workers absenteeism from work as shown in Table 2.

Moreover, female health workers had more leaves than their male counterparts and the time spent at work (leaves) were identified as major factors as shown in Figure 2.

\subsection{Health Facility Factors Contributing to Staff Absenteeism}

Major health center factors included; poor leadership (95.9\%), increased assignment to administrative duties (78.4\%), irregular supervision (91.2\%), poor

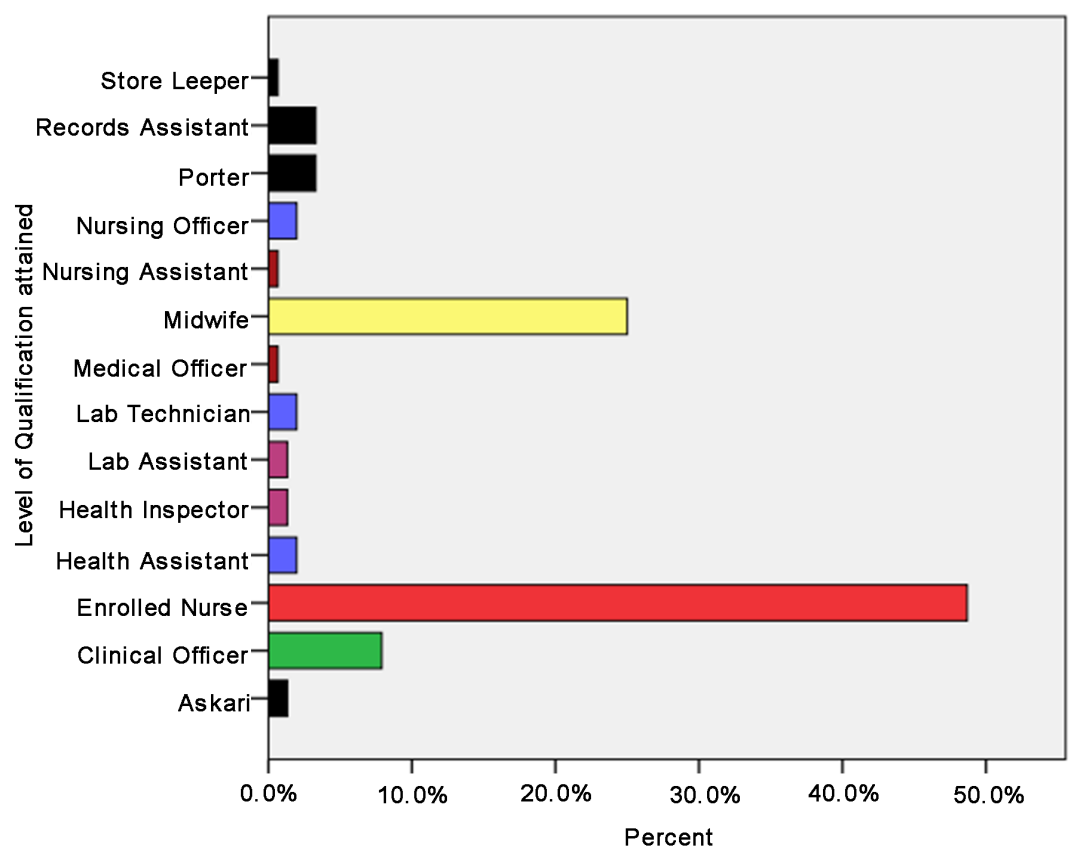

Figure 1. Showing level of qualification in healthcare workers. 
Table 1. Showing population demographics.

\begin{tabular}{|c|c|c|c|c|c|}
\hline & Variable & $\begin{array}{r}\text { Frequenc } \\
\text { par }\end{array}$ & $\begin{array}{l}\text { of sex in } \\
\text { ants }\end{array}$ & Total & $P$-value \\
\hline & & Male & Female & & \\
\hline & $18-30$ & $24(15.8)$ & $35(23)$ & $59(38.8)$ & \\
\hline Age (yrs) & $31-45$ & $22(14.5)$ & $57(37.5)$ & $79(52)$ & 0.283 \\
\hline & $>45$ & $5(3.3)$ & $9(5.9)$ & $14(9.2)$ & \\
\hline & Single & $13(8.6)$ & $17(11.2)$ & 30 (19.7) & \\
\hline & Married & $38(25)$ & $79(52)$ & $117(77)$ & \\
\hline 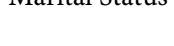 & Separated/Divorced & $0(0)$ & $4(2.6)$ & $4(2.6)$ & 0.270 \\
\hline & Widowed & $0(0)$ & $1(0.7)$ & $1(0.7)$ & \\
\hline Education & Secondary & $1(0.7)$ & $3(2)$ & $4(2.6)$ & \\
\hline Level & Tertiary & $50(32.9)$ & $98(64.5)$ & $148(97.4)$ & 0.114 \\
\hline & $<1 \mathrm{yr}$ & $1(0.7)$ & $1(0.7)$ & $2(1.3)$ & \\
\hline Duration in & $1-2 \mathrm{yrs}$ & $9(5.9)$ & $14(9.2)$ & $23(15.1)$ & 0940 \\
\hline Service & $2-5$ yrs & $22(14.5)$ & $43(28.3)$ & $65(42.8)$ & 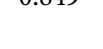 \\
\hline & $>5$ yrs & 19(12.5) & $43(28.3)$ & $62(40.8)$ & \\
\hline Residing & Yes & $30(19.7)$ & $54(35.5)$ & $84(55.3)$ & \\
\hline $\begin{array}{l}\text { within Health } \\
\text { Facility }\end{array}$ & No & $21(13.8)$ & $43(28.3)$ & $64(42.1)$ & 0.530 \\
\hline & $>5 \mathrm{~km}$ & $6(8.3)$ & $12(16.7)$ & $18(25)$ & \\
\hline $\begin{array}{l}\text { Distance of } \\
\text { Residence }\end{array}$ & $5-10 \mathrm{~km}$ & $4(5.6)$ & $6(8.3)$ & $10(13.9)$ & \\
\hline from Health & $10-15 \mathrm{~km}$ & $3(4.2)$ & $9(12.5)$ & $12(16.7)$ & 0.802 \\
\hline & $>15 \mathrm{~km}$ & $9(12.5)$ & $23(31.9)$ & $32(44.4)$ & \\
\hline
\end{tabular}

motivation at work (91.9\%), and poor remuneration (66.4\%) as shown in Table 3, although no significance was shown at $95 \%$ confidence. These where strongly related to delayed salary and high workload.

\subsection{Findings from Key Interviews}

All key informants were in agreement that age, sex, cadre and marital status contributed to staff absenteeism. In addition, they reported to have worked for more than 2 years and had accommodation in the facility.

\subsubsection{Personal Factors Contributing to Staff Absenteeism}

The key informants reported that family responsibilities, having another job, studying without study leave, negative attitude among staff(s), missing and delayed salaries, and sickness and over qualification for a job were among factors contributing to staff(s) absenteeism. The key informants reported that the health assistant(s) and support staff among other cadres were mostly absent without permission from their work stations. 
Table 2. Showing role of personal factors and residence in staff absenteeism.

\begin{tabular}{|c|c|c|c|c|c|}
\hline \multirow{2}{*}{ Parameter } & \multirow{2}{*}{ Variable } & \multicolumn{2}{|c|}{$\begin{array}{l}\text { Frequency (\%) of participants } \\
\text { residing within health facility }\end{array}$} & \multirow{2}{*}{ Total } & \multirow{2}{*}{$P$-value } \\
\hline & & Yes & No & & \\
\hline \multirow{4}{*}{$\begin{array}{l}\text { No. of times staff } \\
\text { absent in past } 1 \mathrm{yr}\end{array}$} & $>4$ times & $6(3.9)$ & $6(3.9)$ & $12(7.9)$ & \multirow{4}{*}{0.349} \\
\hline & $>2$ times & $15(9.9)$ & $15(9.9)$ & $30(19.7)$ & \\
\hline & Once & $22(14.5)$ & $23(15.1)$ & $45(29.6)$ & \\
\hline & None & $41(27)$ & $24(15.8)$ & $65(42.8)$ & \\
\hline \multirow{2}{*}{$\begin{array}{c}\text { Colleague } \\
\text { absenteeism } \\
\text { without permission in } \\
\text { past } 1 \mathrm{yr}\end{array}$} & Yes & $76(51)$ & $60(40.3)$ & $136(91.3)$ & \multirow{2}{*}{0.710} \\
\hline & No & $6(4)$ & $4(2.7)$ & $10(6.7)$ & \\
\hline \multirow{6}{*}{$\begin{array}{c}\text { Reason by Staff for } \\
\text { Absenteeism }\end{array}$} & $\begin{array}{c}\text { Personal sick- } \\
\text { ness }\end{array}$ & $33(23.9)$ & $33(23.9)$ & $66(47.8)$ & \multirow{6}{*}{0.322} \\
\hline & Relative is sick & $10(7.2)$ & $5(3.6)$ & $15(10.9)$ & \\
\hline & $\begin{array}{l}\text { Burial and } \\
\text { Parties }\end{array}$ & $16(11.6)$ & $11(8)$ & $27(19.6)$ & \\
\hline & Schooling & $7(5.1)$ & $9(6.5)$ & $16(11.6)$ & \\
\hline & Another Job & $5(3.6)$ & $5(3.6)$ & $10(7.2)$ & \\
\hline & Other duties & $4(2.9)$ & $0(0)$ & $4(2.9)$ & \\
\hline \multirow{3}{*}{ Family Conflict } & Agree & $55(36.2)$ & $27(17.8)$ & $82(53.9)$ & \multirow{3}{*}{0.003} \\
\hline & Disagree & $16(10.5)$ & $16(10.5)$ & $32(21.1)$ & \\
\hline & Uncertain & $13(8.6)$ & $25(16.4)$ & $38(25)$ & \\
\hline \multirow{3}{*}{ Taken multiple leaves } & Uncertain & $7(4.6)$ & $5(3.3)$ & $12(7.9)$ & \multirow{3}{*}{0.000} \\
\hline & Agree & $20(13.2)$ & $41(27)$ & $61(40.1)$ & \\
\hline & Disagree & $57(37.5)$ & $22(14.5)$ & $79(52)$ & \\
\hline \multirow{3}{*}{$\begin{array}{l}\text { Overstay in One } \\
\text { workstation }\end{array}$} & Uncertain & $9(6)$ & $7(4.6)$ & $16(10.6)$ & \multirow{3}{*}{0.009} \\
\hline & Agree & $30(19.9)$ & $40(26.5)$ & $70(46.4)$ & \\
\hline & Disagree & $45(29.8)$ & $20(13.2)$ & $65(43)$ & \\
\hline \multirow{3}{*}{$\begin{array}{l}\text { Alcohol and drug } \\
\text { substance abuse }\end{array}$} & Uncertain & $15(9.9)$ & $28(18.5)$ & $43(28.5)$ & \multirow{3}{*}{0.002} \\
\hline & Agree & $23(15.2)$ & $18(11.9)$ & $41(27.2)$ & \\
\hline & Disagree & $46(30.5)$ & $21(13.9)$ & $67(44.4)$ & \\
\hline
\end{tabular}

\subsubsection{Health Facility Related Factors Contributing to Staff Absenteeism}

The key informants reported that lack of accommodation, low salaries, drug stock outs, overstaying in one station and overstaffing were contributing factors to staff absenteeism in their facilities. They also reported that duty rosters, daily attendance registers, spot checking in departments and monthly staff wage registers were used to monitor staff attendance in their facilities. 


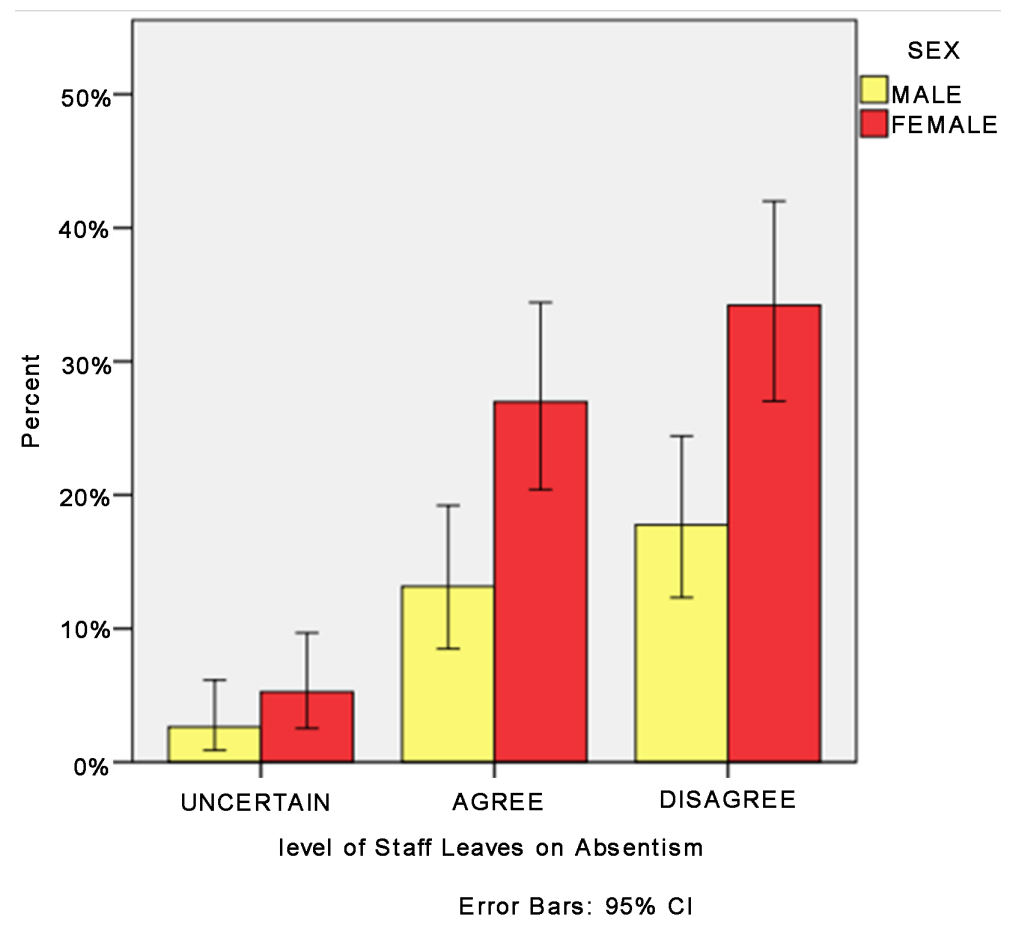

Figure 2. Showing level of staff leaves and sex.

\section{Discussion}

\subsection{Demographic Characteristics and Their Influence on Health Staff Absenteeism}

The study revealed that majority $66.4 \%$ of the health staff were females and only about $33.6 \%$ were males. The nursing profession has been predominated by females and in nature they are more socially bound with family responsibilities and regularly experience physiological changes which lead them to be more absent than their male counterparts. This agrees with the research on the gender-absenteeism relationship indicates that women are more absent than males [2]. This may be due to their traditional responsibilities for caring for the family [11]. The study revealed that slightly more than half $52 \%$ of the respondents were aged between 31 - 45 years, while only $9.2 \%$ were aged above 45 years. This is the active age whereby an individual experiences a lot of responsibilities e.g. taking care of their families, career development among others leading to staff absenteeism. For the ladies this is the time they are struggling to deliver the number of children they want before they clock 45 years whereby they are likely to undergo a major physiological change of menopause. And due to that definitely there will be increased number of leaves i.e. for some sick leaves especially in the first trimesters' the mandatory annual plus maternity leaves leading to high chances of staff absenteeism. Studies examining the relationship between age, and absenteeism have resulted in mixed findings [2] [12]. The proponents of the argument that absenteeism increases with age argue that older staff will exhibit a lower absence rate than younger staff because of a better person-organization fit that emerges over time [6]. However this study disagrees 
Table 3. Showing health facility factors contributing to staff Absenteeism.

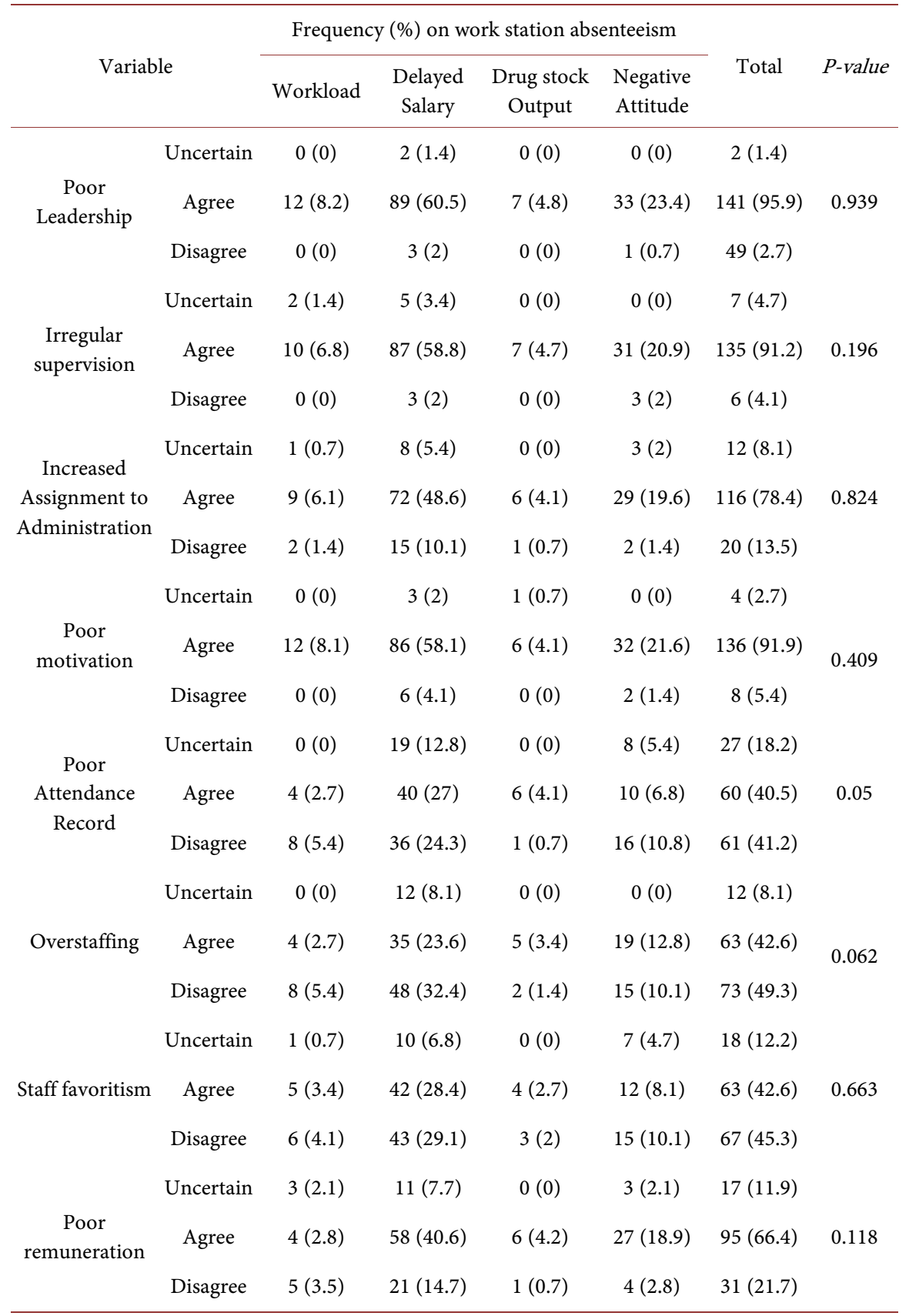

with a previous study which found the majority to be within an age range of 25 30 yrs [13] and these changes would be due to the different study areas. The study also showed that most $77 \%$ of the respondents were married and only $0.7 \%$ was widowed. Married couples have more responsibilities compared to their single counter parts outside their work place e.g. taking care of their families thus contributing to staff absenteeism. In fact one of the key informant expressed his concern that when it comes to the time schools are opening and closing you nearly find like only one staff on duty for almost one week while others will be away ensuring their children are back to school safely. This is in 
line that single men have the lowest absence rates [3]. Marital status also influences absences and appears to do so differentially by sex. Married men, perhaps because of their commitment and obligations to home and family life, are absent less frequently than their single counterparts. Probably because of the same commitment, married female employees are absent more frequently than their never married counterparts. And according to Patton [14], married women have the highest absence rates which they attributed to the difference social responsibilities for gender groups outside the workplace. Amongst married couples, women have been found to contribute less to household income than men, thus leading to the wide spread of opportunism in the workplace especially in the healthcare profession [15]. Moreover, nurses in have taken on advanced roles in the health profession as opposed to doctors [16], thus raising justifiable claims regarding their salaries and workload. This shows the need to revise policy in the health profession of Uganda.

Majority of the health care workers are enrolled nurses (48.7\%), and the least are medical officers $(0.7 \%)$. Higher number of low cadre staffs influences social loafing and hence leading to staff absenteeism as compared to those of higher cadres who are few hence limiting them from being absent from work station. It was noted from the key informants that the health assistants, support staff and nurses/midwives were among the key cadres who were always absent from the work station. Furthermore, majority of participants have been reluctant to upgrade or enroll for refresher courses as it has been found in this study as well. This agrees with a study by [17] has shown that nurses are a major work force in the medical profession and ages amongst them are greatly varied which affects their work morale. The great differences in ages would be due to the fact that nurses enroll at different levels depending on their academic papers at the various technical institutions. A strong sense of collaboration between midwives and nurses has been shown in a study conducted in East, Central and Southern Africa, thus implying that they face related workforce challenges [18]. However it also disagreed with the finding that higher cadre staffs are more absent in the health profession as a result of more engagement in the social-economic spheres matches with the former establishment (unpublished report by Kanyeihabwa). In his study, Kanyeihamba noted $24 \%$ absence of nursing officers compared to only $18 \%$ among the Nursing Assistants. This could have been brought about by the staffing level which was lower by then compared to current at $82 \%$.

The study revealed that majority $44.4 \%$ of respondents who do not reside in the health facility were staying beyond $15 \mathrm{~km}$, while $25 \%$ were staying less than 5 $\mathrm{km}$ away. Those who reside far away from the facility are likely to be absent because of climatic changes e.g. during rainy season roads might be impassable hence delaying to get to work or becoming absent and also some may lack transport completely. One of the health facility in charge noted that staff staying away from the health facility were more absent than their counter part staff accommodated at health facility. She noted that whenever she asks those who absent themselves they say that sometimes they fail to get taxis to bring them to 
their work stations and above all they cannot work for five days in the week because it will imply that all their salaries will be committed to transport. A similar view was earlier observed that staff accommodation impacts on the attendance of staff and improves performance [19].

\subsection{Personal Factors Contributing to Health Staff Absenteeism}

Most of the respondents $47.8 \%$ reported that it was due to personal sickness while $2.9 \%$ had other duties. One of the key informants reported that in most cases when staffs are absent they will report that either they were sick or they were taking care of the sick. However some are in school without study leaves and others are working elsewhere. This study agrees with Kanyemibwa (unpublished report) pointed out sickness as one of these factors, observing that employees tend to cite as one of the major reasons explaining why they do not come to work regularly. This scholar pointed out malaria and HIV/AIDS as the leading diseases cited by employees to explain nonattendance. Moreover stress among nurses due to overtime, lack of support, patient care and workload have been identified as major risk factors in the population [20]. Stress and burnout would be major underlying factors as to why aggression eventually develops against patients [21], thus raising major policy and ethical concerns. The study revealed that more than half $53.9 \%$ of the respondents were agreeing that family conflict was one of the personal factors which were contributing significantly to staff absenteeism, while $21.1 \%$ were disagreeing and the rest were uncertain. Health workers need a lot of counseling to help them cope with their personal challenges. This study agrees with previous findings [20] [22] in which nurse domestic hardships have been shown to affect work quality. Every worker faces hardships in her personal life that don't relate to the workplace. From family troubles, to financial woes, to health problems, to substance abuse, problems in an employee's personal life often manifest at work in the form of absenteeism. Companies can and should hold an employee accountable for her performance at work, including attendance, but if they want to retain her they must also strive to show her flexibility and patience. Personal hardships happen, and in many cases they pass soon enough. Sometimes employees don't have a hard life so much as a full one. Beginning a family, pursuing an education and maintaining relationships all take up a lot of time. Don't be surprised when an employee sometimes needs more time off even though he has a satisfying life both at work and at home. It happens, and these kinds of successful, happy employees have a lot to offer their employers. Companies that insist their employees put work first and everything else second will lose this kind of talent to companies that respect employees who have a lot to live for.

In this study $40.1 \%$ of the respondents were agreeing that different types of leaves contributed greatly to staff absenteeism. Moreover, female health workers had more leaves than their male counterparts and the times spent on leave were identified as major contributing factor. This is because it was regularly observed that most staffs would extend their leaves beyond the stipulated time given. 
Some key informants expressed a concern that they have a full staff list of health workers but you can get like five on different leaves at the same time. For example one noted that she had four staffs on study leave but only two had an official study leave, one on maternity and two on annual leave by the time the study was being carried out. This implies that there was no good coordination between the facility and district on how staffs should apply and be granted study leaves [22]. This has greatly contributed to increased work overload and staff absenteeism in the district. The study revealed that $46.4 \%$ of the respondents were agreeing that overstaying in one station for long contributed a lot to staff absenteeism. Overstaying at work station contributes to health workers absenteeism. Study findings indicate that over staying at a particular workplace reduces workers attitude towards work. They are more absorbed in social activities because they have become part of the community". Such employees are more frequently absent.

The study revealed that $91.2 \%$ of the respondents were agreeing that inadequate supervision was a contributing factor to staff absenteeism. During an in-depth interview with the facility in charges, one quoted that "we are usually overwhelmed with both clinical and administrative work, sometimes it takes me even a week before reaching my facility because of other administrative assignments thus I become inconsistence with internal support supervision" indeed if the head is always not present it will give room for the support mates to always take French leave. Secondly, some other key informants testified that they get little support from local leaders like sub county chiefs and even the health unit management committees. One quoted: "imagine in the previous twelve months our sub county chief has visited the health facility only once, and for the health Unit management committee members only come to the facility when you invite them for the quarterly meetings". This shows that most of the administrative roles are left for the facility in charge. Moreover, the human resource sector at the local government doesn't interact actively with field health care professions. This is because in rural communities (sub-counties), there is no office for a human resource officer who would keep track and motivate healthcare professions serving in isolated regions since Uganda is one of the developing countries with a very high patient to staff ratio, showing the role of retention and training the staff to keep the jobs and work efficiently [23].

This study revealed that $78.4 \%$ of the respondents were agreeing that increased assignment to administrative duties and poor motivation at work place at $91.9 \%$ were contributing significantly to staff absenteeism. This is because all the health facility in charges is bound to do both clinical and administrative work. Most of them have not undergone a management course other than the minimum package which they receive during their career training. Administrative work takes a lot of time for instance the in charge of a Health Centre IV is always overwhelmed because he serves as the in charge of facility and the entire health sub districts thus many assignments leading to absenteeism. Secondly the facilities in charges are not given any administrative allowances thus felt demotivated. This study agrees with [24] Nurse managers have an important role in 
reducing absenteeism by addressing the employees' concerns, which can lead to productivity, increased staff morale, decreased medical hazards and satisfied patients. Retaining staff would decrease time spent orienting and training new staff [25]. One thing that could help retain employees and help decrease absenteeism is employee recognition programs [26].

In this study $95.9 \%$ were agreeing that poor leadership was a contributing factor to staff absenteeism and this was strongly related to delayed salary and high work load. This could be associated with the managers not undergoing a management course before they are assigned the administrative duty. This is logical since having enough nurses to provide good care and that positive relationship between nurses, managers and physicians had the most influence on job satisfaction [27]. In addition, positive leadership, communication, good orientation and professional improvement opportunity, perhaps the overall satisfaction of nurses could be improved and work burnout decreased. The study revealed that $66.4 \%$ of the respondents were agreeing that poor remuneration was one of the factors contributing to staff absenteeism. one of the key informants expressed his concern that the few staffs he had subjected to a disciplinary committee were defending themselves that the salary is not enough to sustain themselves plus their families thus they have to get an extra job for a top up. This study is in line with findings [28] in which low salaries in the nursing profession as major contributors to absenteeism by compelling individuals to take a second job. The primary employer needs the nurse to provide patient 31 care services for limited pay, while on the other hand the secondary employer may make promises to pay nurses adequately for the services rendered. These lead to situations where nurses undertake jobs outside their workplaces, resulting in physical and mental strain, and higher rates of absenteeism [22].

\section{Conclusion and Recommendations}

\subsection{Conclusion}

The study had an elderly population which was predominately of the nursing female nature. The personal sickness, different types of leaves, lack of accommodation in the facilities, poor supervision, poor remuneration, increased assignment to administrative duties, lack of motivation of staff in the rural health centers are major factors for staff absenteeism identified in this study. Moreover, female medical workers have to struggle with family and individual challenges which affect their working efficiency, thus showing a need to revise policy to improve on working environment in rural health centers of Uganda.

\subsection{Recommendations}

The Managers should ensure that those who go for further studies should secure study leaves first, be more vigilant in doing internal support supervision and conduct regular staff meetings and share with staffs the impact of staff absenteeism at their level and beyond. 
Bushenyi district administration should conduct regular spot support supervision to check for staffs who are absent, ensure staff transfers after every 5 years, reward the best performing health workers, and qualified human resource personnel be employed at the sub-county station.

The government should prioritize payments of salaries to avoid unnecessary inconvenience and discouragement of health workers in rural communities. In addition, more recruitment of staff to reduce on the heavy workload, and affirmative action should be promoted to see equal gender representation in the health sector.

\section{Funding}

No funding was offered for this work.

\section{Author Contributions}

All authors contributed equally to the manuscript and approved final version for submission.

\section{Ethical Considerations}

Institutional ethical clearance was obtained prior to commencement of the study.

\section{Informed Consent}

This was got from each participant, the local government offices and individual health center administrators who participated in the study.

\section{References}

[1] Elshout, R., Scherp, E. and van der Feltz-Cornelis, C.M. (2013) Understanding the Link between Leadership Style, Employee Satisfaction, and Absenteeism: A Mixed Methods Design Study in a Mental Health Care Institution. Neuropsychiatric Disease and Treatment, 9, 823-837.

[2] Diestel, S., Wegge, J. and Schmidt, K.-H. (2014) The Impact of Social Context on the Relationship between Individual Job Satisfaction and Absenteeism: The Roles of Different Foci of Job Satisfaction and Work-Unit Absenteeism. Academy of Management Journal, 57, 353-382. https://doi.org/10.5465/amj.2010.1087

[3] Blanca-Gutiérrez, J.J., del C. Jiménez-Díaz, M. and Escalera-Franco, L.F. (2013) Intervenciones eficaces para reducir el absentismo del personal de enfermería hospitalario. [Effective Interventions to Reduce Absenteeism among Hospital Nurses.] Gaceta Sanitaria, 27, 545-551. https://doi.org/10.1016/j.gaceta.2012.09.006

[4] Pedersen, J., Bjorner, J.B., Burr, H. and Christensen, K.B. (2012) Transitions between Sickness Absence, Work, Unemployment, and Disability in Denmark 2004-2008. Scandinavian Journal of Work, Environment \& Health, 38, 516-526. https://doi.org/10.5271/sjweh.3293

[5] Konde-Lule, J., Gitta, S.N., Lindfors, A., Okuonzi, S., Onama, V.O. and Forsberg, B.C. (2010) Private and Public Health Care in Rural Areas of Uganda. BMC Inter- 
national Health and Human Rights, 10, 29. https://doi.org/10.1186/1472-698X-10-29

[6] Johns, G. and Miraglia, M. (2015) The Reliability, Validity, and Accuracy of Self-Reported Absenteeism from Work: A Meta-Analysis. Journal of Occupational Health Psychology, 20, 1-14. https://doi.org/10.1037/a0037754

[7] Uganda National Health Users'/Consumers' Organization (UNHCO) (2010) Establishing Incidence of Health Provider Absenteeism in Bushenyi District.

[8] Government of Uganda (2011) Human Resources for Health Bi-Annual Report. Improving HRH Evidence for Decision Making.

[9] West, M. (2011) NHS Staff Management and Health Service Quality. Heal, 1-16.

[10] Morgan and Krejcie (2012) Sample Size Determination Using Krejcie and Morgan Table. Kenya Projects Organization (KENPRO).

[11] Barthe, B., Messing, K. and Abbas, L. (2011) Strategies Used by Women Workers to Reconcile Family Responsibilities with Atypical Work Schedules in the Service Sector. Work, 40, 1.

[12] Moret, L., et al. (2012) Relationship between Inpatient Satisfaction and Nurse Absenteeism: An Exploratory Study using WHO-PATH Performance Indicators in France. BMC Research Notes, 5, 83. https://doi.org/10.1186/1756-0500-5-83

[13] Mogre, V., Ansah, G.A., Marfo, D.N. and Garti, H.A. (2015) Assessing Nurses' Knowledge Levels in the Nutritional Management of Diabetes. International Journal of Africa Nursing Sciences, 3, 40-43.

[14] Patton, E. and Johns, G. (2012) Sex or Gender? The Enigma of Women's Elevated Absenteeism. Gender and the Dysfunctional Workplace. 149-163.

[15] Iversen, V., Jackson, C., Kebede, B., Munro, A. and Verschoor, A. (2011) Do Spouses Realise Cooperative Gains? Experimental Evidence from Rural Uganda. World Development, 39, 569-578.

[16] Delamaire, M. and Lafortune, G. (2010) Nurses in Advanced Roles. OCDE, OECD Heal, No. 54. https://doi.org/10.1787/5kmbrcfms5g7-en

[17] Van der Colff, J.J. and Rothmann, S. (2014) Burnout of Registered Nurses in South Africa. Journal of Nursing Management, 22, 630-642. https://doi.org/10.1111/j.1365-2834.2012.01467.x

[18] McCarthy, C.F. and Riley, P.L. (2012) The African Health Profession Regulatory Collaborative for Nurses and Midwives. Human Resources for Health, 10, 26. https://doi.org/10.1186/1478-4491-10-26

[19] Gosselin, E., Lemyre, L. and Corneil, W. (2013) Presenteeism and Absenteeism: Differentiated Understanding of Related Phenomena. Journal of Occupational Health Psychology, 18, 75-86. https://doi.org/10.1037/a0030932

[20] Rothmann, S., van der Colff, J.J. and Rothmann, J.C. (2006) Occupational Stress of Nurses in South Africa. Curationis, 29, 22-33. https://doi.org/10.4102/curationis.v29i2.1069

[21] Hills, D. (2008) Relationships between Aggression Management Training, Perceived Self-Efficacy and Rural General Hospital Nurses' Experiences of Patient Aggression. Contemporary Nurse, 31, 20-31. https://doi.org/10.5172/conu.673.31.1.20

[22] Vignoli, M., Guglielmi, D., Bonfiglioli, R. and Violante, F.S. (2016) How Job Demands Affect Absenteeism? The Mediating Role of Work-Family Conflict and Exhaustion. International Archives of Occupational and Environmental Health, 89, 23-31. https://doi.org/10.1007/s00420-015-1048-8 
[23] O’Neil, M. (2009) Competency Gaps in Human Resource Management in the Health Sector: An Exploratory Study of Ethiopia, Kenya, Tanzania, and Uganda. Management Sciences for Health, 1-4.

[24] Mudaly, P. and Nkosi, Z.Z. (2014) Factors Influencing Nurse Absenteeism in a General Hospital in Durban, South Africa. Journal of Nursing Management, 623-631.

[25] Singh, N.N., Lancioni, G.E., Karazsia, B.T., Myers, R.E., Winton, A.S.W., Latham, L.L. and Nugent, K. (2015) Effects of Training Staff in MBPBS on the Use of Physical Restraints, Staff Stress and Turnover, Staff and Peer Injuries, and Cost Effectiveness in Developmental Disabilities. Mindfulness, 6, 926-937. https://doi.org/10.1007/s12671-014-0369-0

[26] Sandhya, K. and Pradeep Kumar, D. (2011) Employee Retention by Motivation. Indian Journal of Science and Technology, 4, 1778-1782.

[27] Cummings, G.G., Olson, K., Hayduk, L., Bakker, D., Fitch, M., Green, E., Butler, L., and Conlon, M. (2008) The Relationship between Nursing Leadership and Nurses' Job Satisfaction in Canadian Oncology Work Environments. Journal of Nursing Management, 16, 508-518. https://doi.org/10.1111/j.1365-2834.2008.00897.x

[28] Kaddourah, B.T., Khalidi, A., Abu-Shaheen, A.K. and Al-Tannir, M.A. (2013) Factors Impacting Job Satisfaction among Nurses from a Tertiary Care Centre. Journal of Clinical Nursing, 22, 3153-3159. https://doi.org/10.1111/jocn.12261 